Abstracta Iranica Iranica

Revue bibliographique pour le domaine irano-aryen

Volume 42-43 | 2021

Comptes rendus des publications de 2019-2020

\title{
Ladislav Stančo, Petra Tušlová (eds.) Sherabad Oasis. Tracing Historical Landscape in Southern Uzbekistan
}

Johanna Lhuillier

\section{OpenEdition}

1 Journals

\section{Édition électronique}

URL : https://journals.openedition.org/abstractairanica/52254

DOI : 10.4000/abstractairanica.52254

ISSN : 1961-960X

Éditeur :

CNRS (UMR 7528 Mondes iraniens et indiens), Éditions de l'IFRI

Référence électronique

Johanna Lhuillier, «Ladislav Stančo, Petra Tušlová (eds.) Sherabad Oasis. Tracing Historical Landscape in Southern Uzbekistan », Abstracta Iranica [En ligne], Volume 42-43 | 2021, document 5, mis en ligne le 15 avril 2021, consulté le 28 décembre 2022. URL : http://journals.openedition.org/abstractairanica/ 52254 ; DOI : https://doi.org/10.4000/abstractairanica.52254

Ce document a été généré automatiquement le 28 décembre 2022.

Tous droits réservés 


\section{Ladislav Stančo, Petra Tušlová (eds.) Sherabad Oasis. Tracing Historical Landscape in Southern Uzbekistan}

Johanna Lhuillier

\section{RÉFÉRENCE}

Ladislav Stančo, Petra Tušlová (eds.) Sherabad Oasis. Tracing Historical Landscape in Southern Uzbekistan. Reports of Czech-Uzbekistani Archaeological Mission in southern Uzbekistan. Vol. 2. Prague : Charles University/Karolinum Press, 2020, 495 p. ill.

1 Cet ouvrage fait le bilan des opérations de terrain menées entre 2008 et 2011 par la mission archéologique tchéco-ouzbèke dans l'Oasis de Sherabad sous la direction de Ladislav Stančo et de Shapulat Shaydullaev. Elles ont reposé sur l'approche spatiale de cette micro-région située dans le sud de l'Ouzbékistan, dans la province du SurkhanDarya, avec l'objectif principal d'étudier les dynamiques de peuplement dans le temps long.

2 Le volume est organisé en 6 parties principales, principalement rédigées sous la plume des deux éditeurs scientifiques, avec quelques contributions d'autres membres de leur équipe (Sh. Shaydullaev, A. Shaydullaev, A. Danielisová, T. Annaev, M. Kobierská). La première partie, assez courte, présente les conditions géographiques, climatiques et hydrauliques et fait le bilan des précédentes recherches dans la région.

3 Les deuxième et troisième parties sont complémentaires et présentent les méthodes et les données acquises lors des différentes prospections, qui incluent l'analyse de l'imagerie satellite et des cartes topographiques, ainsi que des prospections pédestres complétées par quelques sondages ponctuels. Elles ont permis l'établissement d'un système d'information géographique dont l'objectif était de déboucher sur la réalisation d'une carte archéologique de la région. 
4 C'est dans les quatrième et cinquième parties que les résultats sont véritablement détaillés et commentés. La quatrième partie dresse un catalogue complet de tous les sites recensés. Pour chaque site, une fiche descriptive est fournie, accompagnée d'une vue satellitaire ou d'un plan topographique et d'une vue générale. La cinquième partie constitue le cœur de l'ouvrage. Elle s'attache à suivre l'évolution du motif de peuplement de l'Oasis de Sherabad en livrant une analyse chronologique de l'ensemble de ces sites depuis l'âge du Bronze jusqu'à la période post-mongole, tout en incluant certains éléments d'analyse plus limités jusqu'à la période contemporaine : 4 sites de l'âge du Bronze, 10 sites de l'âge du Fer (qui inclut la période " achéménide » ou Yaz III), 8 sites hellénistiques, 47 sites kouchans, 44 sites médiévaux, 14 sites post-mongoles. Chaque période est illustrée par une carte de l'ensemble des sites.

5 Concernant la période "achéménide ", le site de Pachmaktepa a été complètement détruit par les récentes activités agricoles et les sites principaux restent Jandavlattepa (intensivement étudié par les auteurs et bien publié par ailleurs) et Talashkantepa (étudié et publié par E. Rtveladze, Sh. Pidaev, Sh. Shaydullaev). La fondation du site de Yalangoyokotatepa est attribuée par les auteurs à cette période, mais le site est occupé actuellement par un cimetière moderne qui y rend toute fouille impossible. D'autres sites $\left(n^{\circ} 26,39\right.$ et 138$)$ se rattachent également à cette période. Selon les auteurs, les sites sont alors organisés selon un principe rayonnant, avec un centre (Jandavlattepa, fondé au début de l'âge du Fer) et des sites satellites, probablement des fermes. Certains de ces sites restent occupés lors de la période hellénistique, mais aucune hiérarchie ne se dégage plus et rien n'indique une augmentation de la population. C'est seulement lors de la période kouchane qu'elle croît et que l'irrigation se développe de manière significative dans la région.

6 Le matériel céramique récolté dans ces divers sites est traité dans la sixième partie. On peut regretter que les autres types de matériel découvert ne soient que très partiellement abordés dans ce volume (dans cette même partie), mais l'étude de la céramique, qui constitue la majorité du matériel, est complète, puisqu'elle est basée sur un peu plus de 1000 tessons diagnostiques ramassés sur 54 sites, et bien illustrée par de nombreuses planches.

\section{AUTEURS}

\section{JOHANNA LHUILLIER}

UMR 5133 CNRS-Université de Lyon 